\title{
Mechanical Properties of Renewable Polymer with Thermoplastics Endurance to Ultraviolet irradiation Exposure
}

\author{
Nurul Syamimi M. Salim ${ }^{1,}$, Anika Zafiah M. Rus ${ }^{1}$, and Masnadia Mashuri ${ }^{1}$ \\ ${ }^{1}$ Faculty of Mechanical and Manufacturing, University Tun Hussein Onn Malaysia (UTHM), Parit \\ Raja, 86400, Batu Pahat, Malaysia
}

\begin{abstract}
At present the disposal of waste tyre rubber (WTR) has become a major waste management problem in the world. Therefore in this study, polymer blended based on Polyethylene which is Low Density Polyethylene (LDPE) or High Density Polyethylene (HDPE), with Renewable Polymer (RP) and waste tyre rubber (WTR) is prepared via injection molding. Blended polymer such as LDPE/RP/WTR and $\mathrm{HDPE} / \mathrm{RP} / \mathrm{WTR}$ is known as LRT and HRT respectively. The preparation of polymer blend steps start with the preparation of RP. The RP is prepared by crosslinking the renewable monomer with Polymethane Polyphenyl Isocyanate (MDI) at composition ratio of 1:0.5. The second steps involved by adding $10 \mathrm{gm}$ of liquid RP prepared earlier on with fixed amount of LDPE and HDPE of $100 \mathrm{gm}$. Then the blended LDPE/RP or HDPE/RP namely as LR or HR respectively is further added with WTR with different percentages ratio of $5 \%, 10 \%$ and $15 \%$. The manually blended polymer mixture and filler is then melt mixing using injection moulding to fabricate the tensile specimen for mechanical tensile test and physical determination such as density, distribution of WTR in polymer blend and surface fracture morphology using scanning electron microscope. The samples were then exposed to UV irradiation exposure in UV Accelerated Weathering for $500,1000,1500,2000,2500$ and 3000 hours to evaluate the photostability of the polymer blends. The optimum amount of WTR ratio composition is at $5 \%$ for both LRT and HRT blends which indicate the stability of polymer blends towards UV irradiation exposure at 1000hours.
\end{abstract}

\section{Introduction}

At present most of industrial uses only synthetic polymer from petroleum and natural gas resources such as polyethylene, polypropylene and polyvinyl chloride. However, this type of polymer materials that is not renewable. In addition, the polymer of this type has the disadvantage because it can cause environmental pollution, congestion landfills and depend entirely on limited natural resources such as petroleum [1]. Renewable polymer is a renewable material because its ability to undergo degradation (decomposition) in the biosphere that is associated with micro-organisms, enzyme or under a state of

\footnotetext{
${ }^{*}$ Corresponding author : nurulsyamimisalim@gmail.com
} 
nature[2]. While, renewable resources for the conversion of renewable polymer is originated from vegetable oils. The main constituents of vegetable oils are triacylglycerols, which are the product of esterification of glycerol with three fatty acids. Fatty acids account for $95 \%$ of the total weight of triglycerides and their content is characteristic for each vegetable oil [3]. In polymer industry, waste vegetable oils which represent a major potential source of chemicals have been utilized as an alternative feedstock for sustainable monomers.

New technologies, processes and resources are currently under research due to the current worldwide energy panorama. Dramatic growth in the number of used tyres around the globe was recorded due to increasing number of vehicles on the road. Approximately 800 million tyres are discarded around the globe annually [4]. This figure is estimated to increase by $2 \%$ every year. The annual global production of tyres is about 1.4 billion unit, which corresponds to an estimated 17 million tonnes of used tyres each year [5].

Waste tyre particle (WTP) falls into this kind of solid residues and it is managed as waste even if it is going to be recycled or re-manufactured. This is a burden that adds significant cost over disposal and in many cases acts as a barrier to improve resource efficiency [6]. The scientific community's effort in finding ways to reduce tyre waste has leaded to intense research on rubber recycling. The technology of polymer blending has emerged as a useful tool in tailoring polymers to the needs of the end users. Accordingly, blending with waste rubber is important both from the point of view of disposal of waste and the reduction in the product cost [7].

The specimen of renewable polymer (RP) from monomer based on palm oil is reinforced with synthetic polymer, Low Density Polyethylene (LDPE) or High Density Polyethylene (HDPE) and mixed with waste tyre rubber (WTR) as filler. The specimen of HDPE/RP, LDPE/RP, WTP/HDPE and WTP/LDPE were irradiated under ultraviolet (UV) radiation exposure. The tensile test tested to study the effect of UV irradiation exposure on the mechanical properties of specimens the LDPE/RP, HDPE/RP, WTR/LDPE and WTR/HDPE.

\section{Experimental}

The raw materials involved for the experimental study were high density polyethylene $(\mathrm{HDPE})$ density $=0.957 \mathrm{~g} / \mathrm{cm} 3$, (melt index $=4 \mathrm{~g} / 10 \mathrm{~min}$, vicat softening point $=124{ }^{\circ} \mathrm{C}$ ), low density polyethylene (LDPE) density $=0.922 \mathrm{~g} / \mathrm{cm} 3$, (melt index $=5 \mathrm{~g} / 10 \mathrm{~min}$, , vicat softening point $=93{ }^{\circ} \mathrm{C}$ ), flexible and rigid Polymethane Polyphenyl Isocyanate (Modified polymeric-MDI) (viscosity at $25^{\circ} \mathrm{C}=120-160 \mathrm{cps}$, specific gravity at $25{ }^{\circ} \mathrm{C}=1.18-1.20$ $\mathrm{g} / \mathrm{ml}$, NCO content, $\% \mathrm{wt}=26.3-27.3$ ), renewable monomers and waste tyre rubber (WTR). The monomer conversions from waste vegetable oils are started with in-house catalyst preparation to generate the epoxies from the unsaturated fatty blends. The liquid monomer is mixed with crosslinker and with HDPE and LDPE until solidifies. The proportion ratio of crosslinker and monomer is 1:0.5. This process is repeated with different ratio of renewable-polymer (RP) and WTR of $5 \%, 10 \%$ and $15 \%$.

LDPE/RP, HDPE/RP, WTR/LDPE and WTR/HDPE were fed in the injection molding machine (Nissei Horizontal Screw Type Injection Molding NP7) equipped with mold of tensile specimens according to ISO $527(5 \mathrm{~A})$. The processing temperature for nozzle, front, middle, rear 1 and rear 2 for LDPE were $185^{\circ} \mathrm{C}, 180^{\circ} \mathrm{C}, 175^{\circ} \mathrm{C}, 170^{\circ} \mathrm{C}$ and $165^{\circ} \mathrm{C}$ while, for HDPE were $205^{\circ} \mathrm{C}, 195^{\circ} \mathrm{C}, 180^{\circ} \mathrm{C}, 175^{\circ} \mathrm{C}$ and $165^{\circ} \mathrm{C}$. The injection pressure for LDPE and HDPE were 43.3 and 96.6 MPa respectively. Dumbbell shape samples produced from injection moulding was exposed to the UV light in UV Lamp Tested Model HD-703 (Haida International Equipment Co., LTD) at different exposure time at $50{ }^{\circ} \mathrm{C}$. Different UV exposure time was conducted for each group of 5 sample to calculate the average value of mechanical testing. The UV exposed time set 500, 1000, 1500, 2000, 2500 and 3000 hour. 


\section{Result and discussion}

\subsection{Mechanical Properties of LDPE/RP and HDPE/RP blends.}

The mechanical properties of the blended were analyzed based on their tensile strength and strain or elongation at break as shown in Figure 1a and Figure 1b. The HDPE provides ductility that exhibit brittle behaviour with a subsequent loss of toughness to the blended materials. The addition of RP generally increases the toughness and decreases the strength of the blends. This could be due to the soft properties of the RP. Meanwhile, the elongation at break increased. The higher tensile strain of HDPE/RP blends compared to neat HDPE may also be due to plasticization effect. Based on these results, when the RP is added with crosslinker, it may act as filler as it improves the tensile strain values.

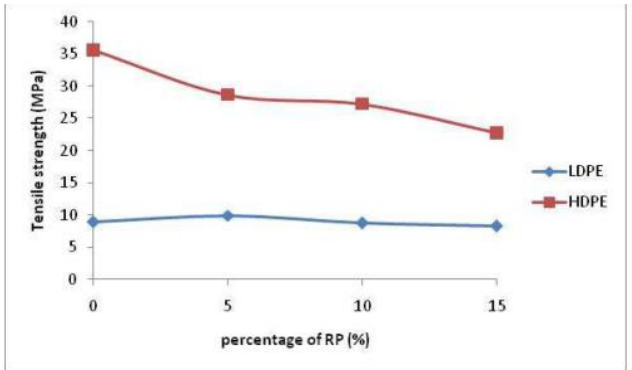

(a)

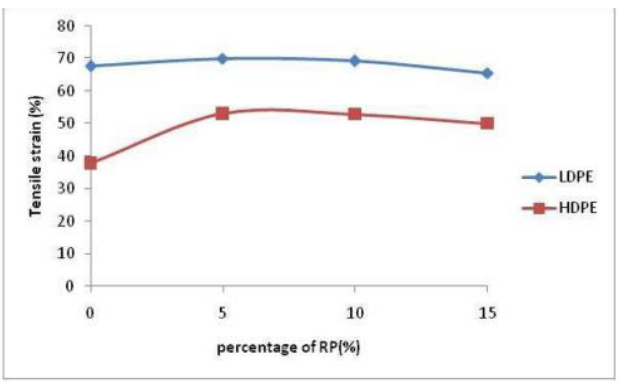

(b)

Fig.1. LDPE/RP and HDPE/RP blends after UV Exposure with (a) Tensile Strength (b) Tensile Strain.

Besides that, the tensile strain of the LDPE/RP blends is observed to be higher than the HDPE/RP blends. The high value of elongation at break for the LDPE/RP blends is due to the more flexible properties. This allows it to significantly yield before breaking, leading to a high value of tensile strain. Therefore, LDPE/RP is comparatively more flexible than HDPE/RP.

\subsection{Effects of UV irradiation exposure on tensile strength.}

Figure $2 \mathrm{a}$ and Figure $2 \mathrm{~b}$ shows the graph of tensile strength of LDPE/RP and HDPE/RP with consistent ratio of RP of $10 \%$ and waste tyre rubber (WTR) of 5\%,10\% and $15 \%$. The samples is namely as, L, LR, LRT5, LRT10, LRT15, H, HR, HRT5, HRT10 and HRT15 blends. Where the abbreviation of $\mathrm{L}$ is for LDPE, $\mathrm{H}$ for HDPE, $\mathrm{R}$ for renewable polymer, $\mathrm{T}$ is for waste tyre rubber with proportion ratio of 5,10 and $15 \%$. The presence of the WTR ratio did not improve the strength properties of the LDPE samples. Meanwhile WTR contributed better strength on the $\mathrm{H}$ and HR. It is clearly shows that the HRT5 strength values were approaching the neat HDPE from the Figure $2 \mathrm{a}$. It is also noted that the UV irradiation exposure also give influence to the crosslink process between RP and the WTR. 


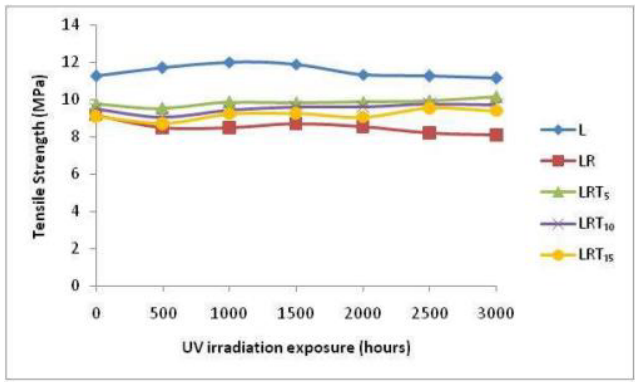

(a)

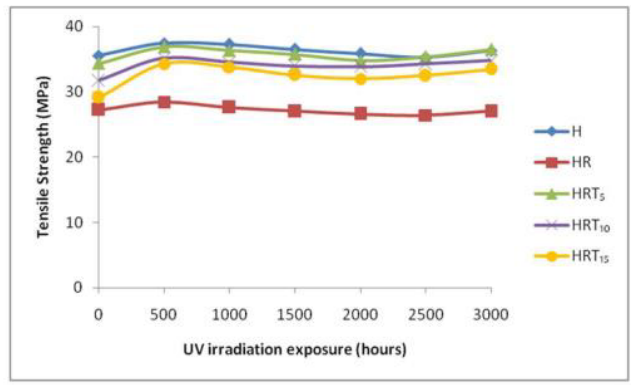

(b)

Fig. 2. Effects of UV irradiation exposure on tensile strength for (a) LDPE and (b) HDPE.

H, HR, HRT5, HRT10 and HRT15 show the highest value of the tensile strength compare to the L, LR, LRT5, LRT10 and LRT15. However the trend starts to decreases after HRT5. The increase of the WTR percentages content will decrease the mechanical properties of HDPE and LDPE blends.

At the beginning the HR facing the decrement of $23.35 \%$, then the small increment of $3.35 \%$ from HRT5 and then decrement start to begin from HRT10 and HRT15 with value of $10.80 \%$ and $17.95 \%$ respectively. After UV irradiation exposure the decrement trend are much slower than before the UV irradiation exposure of LDPE or HDPE blends.

It can be seen that by increasing the WTR content the tensile strength of LR, LRT5, LRT10, LRT15, HR, HRT5, HRT10 and HRT15 was decrease due to the attributed of WTR content. The WTR still remain as the dispersed in the blend while the LDPE or HDPE was bearing the tensile strength alone. Previous studies [8], stated several reasons for the decrease in tensile strength due to the decreasing of the blends rigidity.

It is well known that the WTR is quite hard to dispose and highly resistance to the degradation due to the various different chemical components on it. In conjunction with that, WTR particle induces to the photostability of the LRT5, LRT10, LRT15, HRT5, HRT10 and HRT15 blend because WTR particle did not give any reactions during the UV irradiation exposure process. UV irradiation exposures not lead the crosslinking between RP, WTR and the matrix. However, due to the lack of adhesion and low interfacial bonding, WTR particle lead to the decreasing on mechanical properties. The addition of WTR in the polymer blend is an advantages in order to recycle the scrap tyres. However, according to Pilar [9], WTR use as an additive should be at low amounts which are less than $10 \% \mathrm{wt}$.

\subsection{Effects of UV irradiation exposure on tensile strain.}

Figure $3 \mathrm{a}$ and $3 \mathrm{~b}$ shows the graph of strain (\%) for samples of polymer blends. Every group of polymer blends samples show fluctuate trend. It is noted that the presence of the WTR influence the strain properties. The fluctuate trend for all the samples of LRT5 show the highest improvement if compare to the sample of LR, LRT10 and LRT15. $1.54 \%$ difference from comparison of unirradiated and 3000 hour on UV irradiation exposure. The LRT5 show the most significant improvement of strain (\%). At 500 hour UV irradiation exposure for LRT10 show the biggest decrement with $13.17 \%$. However the tensile strength of HRT5, HRT10 and HRT15 slowly increased as shown in Figure 3b. The strain trend shows almost the same for all samples. However, lowest strain of H, HR, HRT5, HRT10 and HRT15 as compared to the L, LR, LRT5, LRT10 and LRT15. 


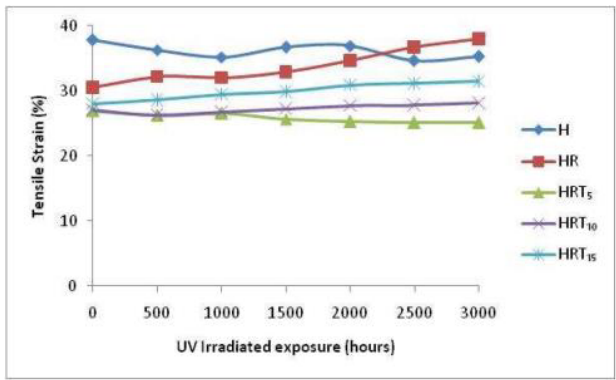

(a)

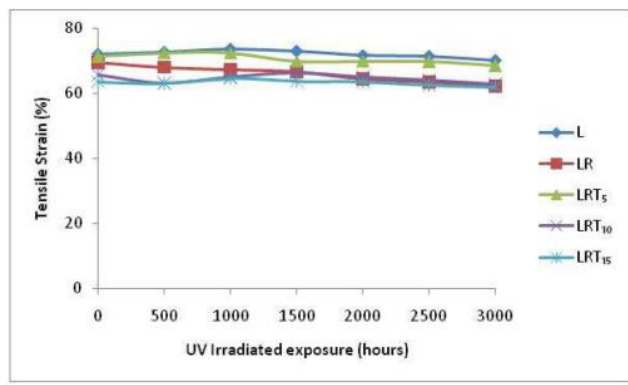

(b)

Fig. 3. Effects of UV irradiation exposure on tensile strain for (a) LDPE and (b) HDPE.

Neat LDPE still have highest strain compare to those samples added with WTR as shown in Figure 3a. LRT15 show the lowest value on strain. However, LRT5 shows the better influence of WTR. $5 \%$ of WTR enhance the strain on LDPE approaching the neat LDPE value.

Figure $3 \mathrm{~b}$ show the effects of UV irradiation exposure on strain for H, HR, HRT5, HRT10 and HRT15. The trend shows that there are slight increments of strain for HRT5, HRT10 and HRT15. Meanwhile, at 1000 hours until 3000 hours, the tensile strain of HR increases. It is well known that HDPE have high crystallinity that will make it hard to deform and cause to break in low strain.

From the previous study [10], it is also proven that by adding the WTR on HDPE blend will lead the strain to decrease. However, in this study show that there are some increments on the strain after UV irradiated exposure. It is believe, this situation happen due to the increase of adhesion between the interfacial of WTR and the matrix LDPE or HDPE. Thus this condition lead to WTR and HDPE blends become miscible blends, which reducing two separate phases on the blend that causing strain to increase slightly.

\section{Conclusion}

The processing conditions of polymer blends of LDPE and HDPE by injection molding were determined and analyzed. The initial processing conditions of the standard LDPE and HDPE thermoplastic were used as references. It was concluded that the processing conditions by injection molding were exactly the same to that of neat LDPE. For the HDPE/RP blends, increases in the parameters used in injection molding were required. Tensile strength and elongation at break increased with increasing RP content at low compositions and started to decrease at high RP content for the LDPE/RP blends. However, the tensile strength and strain of the LDPE/RP blends were generally better than the neat LDPE. Therefore, not only does the presence of RP in the blends provide sustainable characteristics, but it also improves the mechanical properties. These results comply with the properties of pure LDPE and HDPE. Apart from the changing ratios of RP to LDPE or HDPE, the processing temperature was also considered to have an influence on the mechanical properties of the blends. The effects of sustainable polymer to the LDPE or HDPE have become more significant as the polymer blends has been exposed to the UV irradiation.

The author would like to thank the Malaysian Government and University Tun Hussein Onn Malaysia (UTHM), Johor and Postgraduate Incentive Research Grant Vot U222 and Malaysian Technical University Centre of Excellence (MTUN CoE) for supporting this research study under research grant Vot 1481 . 


\section{References}

1. S. Wiwin, G.S. Monica, T. Wega, Triyono, A. Ria, I.F.F. Iip, Procedia Environmental Sciences , 20, 215 (2014)

2. R. Chandra, R. Rustgi, Prog. Polym. Sci., 23(7), 1273 (2000)

3. M.D.E. Lucas, M.A.R. Meier, Eur. Polym. J., 47(5), 837 (2010)

4. P.J.H.V. Beukering, M.A. Janssen, Resour. Conserv. Recycl., 33(4), 235 (2001)

5. M. Sienkiewicz, J.K. Lipka, H. Janik, A. Balas, Waste Manage., 32(10), 1742 (2012)

6. S. Ramarad, M. Khalid, C.T. Ratnam, A.L. Chuah, W. Rashmi, Prog. Mater. Sci., 72, 100 (2015)

7. M.M. Hassan, N.A. Badway, A.M. Gamal, M.Y. Elnaggar, E.S.A. Hegazy, Nucl. Instrum. Meth. B., 268(9), 1427 (2010)

8. H.H.R. Cui, M.R. Kessler, Polym. Degrad. Stabil, 98(11), 2357 (2013)

9. M.A. Salem, Egypt J. Sol., 24(2), 141 (2001)

10. I. Grigoriadou, Compos. Part B-Eng., 55, 407 (2013)

11. S.M. Tamboli, S.T. Mhaske, D.D. Kale, Indian J. Chem. Techn., 11(6), 853 (2004) 